\title{
Technology management and strategy composition: innovation of IC foundry
}

\author{
Grace T. R. Lin - Hsiao Chen Yu • Aaron Y. L. Hsieh • \\ James C. Chou
}

Received: 11 July 2008 / Accepted: 22 March 2009 / Published online: 9 April 2009

(C) Springer Science+Business Media, LLC 2009

\begin{abstract}
The goals of this research are two-tiered: The first goal is to analyze the evaluation criteria used by integrated circuit (IC) designers when selecting foundry service providers. The second goal is to use an in-depth case study on the global IC foundry leader, TSMC, to explore the strategic compositions of IC foundry's process development, since the process technology has been found, through our survey at the prior stage, to be the most significant evaluation criterion in view of competitiveness in the customer market. As a result, for the foundry industry, technology no longer counts for everything, although it is a priority; coordinated strategies, in contrast, should assure more business merits for all concerned. This study has drawn the strategy matrix with eight categories of IC foundry process strategies.
\end{abstract}

Keywords IC foundry - IC designers - Evaluation criteria MCDM $\cdot$ AHP $\cdot$ IC process strategy model

\section{Introduction}

In 2004, worldwide revenue generated by pure-play integrated circuit (IC) foundries reached $\$ 16.8$ billion while that from integrated device manufacturer (IDM) foundries reached $\$ 3$ billion. The surge in revenue of pure-play IC

G. T. R. Lin $(\varangle)$ · H. C. Yu · A. Y. L. Hsieh · J. C. Chou

The Institute of Technology Management,

National Chiao Tung University, Hsinchu City, Taiwan

e-mail: gtrl@faculty.nctu.edu.tw

H. C. Yu

e-mail: chengyu@mail.nctu.edu.tw

A. Y. L. Hsieh

e-mail: ylhsieh@tsmc.com

J. C. Chou

e-mail: c.james.chou@gmail.com foundries stemmed from its aggressive expansion of capacity, increased demand by fabled IC design houses, and outsourced opportunities from IDMs. The top seven pure-play foundry companies and their estimated market shares in 2007 were as follows: Taiwan Superconductor Manufacturing Company (TSMC) Taiwan (47\%), UMC Taiwan (18\%), SMIC China (7\%), Chartered Singapore (7\%), TI USA (3\%), IBM USA (2.7\%), Dongbu South Korea (2.4\%). The rest were shared by foundries with no more than $2 \%$ of market share each (IC Insights 2008).

Our research objectives are two-tiered: The first goal is to analyze the evaluation criteria used by IC designers when selecting foundry service providers. We interviewed the managers of foundry company customer service departments and the purchasing departments of Taiwan's IC designers and used the analytic hierarchy process (AHP) method proposed by Saaty (1980) to determine the areas of top concern with respect to foundry evaluation criteria. Second, understanding that IC process technology is the most critical consideration of IC designers while choosing foundry service providers and that existing studies in the IC foundry industry mostly focus on the fields of production, marketing, human resource management, and finance, but lack the embodied elaboration on IC foundry process strategies, this research explored the strategic compositions of IC foundry's process development by drawing upon literature review, industry interviews, secondary data analysis, and an in-depth case study of TSMC, the world leader in IC foundry. The management logic of IC foundry can be characterized by four competitive strategies, namely the cost leadership strategy, the differentiation strategy, the focused customer differentiation strategy, and the focused customer low cost strategy. The concept of product life cycle is also employed to help construct our strategic model of IC foundry process development. This part took the broad framework developed in theoretical and 
empirical studies with the goal of putting forward appropriate process strategies in different process life cycles. Finally, overall process strategies were suggested based on the proposed IC foundry strategic model.

\section{Multi-criteria decision-making}

This section explores how Taiwan's IC designers evaluate foundry services using a multi-criteria decision-making (MCDM) model.

\section{Related theories and model construction}

The MCDM method is mostly devoted to particular aspects of multi-criteria optimization: multi-objective integer programming, multi-objective combinatorial optimization, vector optimization, multi-objective evolutionary methods, applications of MCDM, MCDM software, goal programming, and so on (Perry and Moffat 1977; Tzeng 1977; Tzeng et al. 1992; Tzeng and Tsaur 1993; Triantaphyllou 2000; Kasanen et al. 2000; Corner et al. 2001; Chu et al. 2008). To build a research model that accurately reflects the concerns of most IC designers, Shyu et al. (2003) interviewed several key managers of global IC design houses and foundry service providers. A consensus of IC designers' three top-level concerns about foundry operators was as follows:

1. Foundry processing technologies,

2. Customer service and logistical support, and

3. Geographic location.

Under foundry processing technology concerns, they defined five evaluation criteria: (1) whether an operator has advanced semiconductor technologies, (2) whether the production yield is high, (3) whether the production schedule and capacity are flexible, (4) whether the cost is low, and (5) whether the product quality and reliability are high. Under customer services and logistical support concerns, they defined five evaluation criteria: (1) whether an operator provides real time information on the status of customers' orders, (2) whether there exists a long-term strategic partnership, (3) whether an operator has a short cycle time and on-time delivery, (4) whether an operator provides technical support responsively, and (5) whether an operator can protect clients' trade secrets and intellectual property rights. Finally, under geographic location concerns, they defined four evaluation criteria: (1) whether the region has political and social stability, (2) whether the region provides customs and tax breaks, (3) whether location risks are diversified, and (4) whether the region has formed a cluster of providers and buyers.

According to Lo et al. (2005), the characteristics of pure play foundry business involve the following: (1) pure play foundries show integrity with customers and vendors and possess employees who tell the truth and maintain an objective, consistent, and impartial attitude; (2) pure play foundries maintain a consistent focus on core business, not distracting themselves with other pursuits; (3) pure play foundries recognize that the semiconductor business has no national boundaries and that to be competitive anywhere, they must be competitive everywhere; and (4) pure play foundries realize that unceasing innovation is the wellspring of growth. Consequently, cooperation and coordination are vital to all sectors of foundry business, from strategic planning to marketing, management, technology, and production. Lo et al.'s (2005) study incorporated four-aspect representation measuring the manufacturing competence and development strategies of pure wafer foundries using an AHP evaluation hierarchy structure. Researchers investigated operation production, marketing, technology, and management activities, which are the four phases to determine the participant cognition of relative importance (weight). In addition, some other research studies, such as managerial analyses of the IC foundry industry from Chen et al. (2004), contended that both the enlargement of production capacity and technological research and development (R\&D) should be spotlights for developing competitive and current IC foundry strategies.

Incorporating all of the above, this research constructed an MCDM model considering the aspects of technology, production, customer service and support, and manufacturing location in order to determine the areas of top concern with respect to foundry evaluation criteria from the perspective of the IC designers. Our MCDM model comprises four first-tier concerns and sixteen second-tier evaluation criteria, as shown in Fig. 1.

\section{AHP and determining the weights}

The AHP method is a multi-criteria method of analysis based on an additive weighting process, in which several relevant attributes are represented through their relative importance (Saaty 1980). AHP has been extensively applied by academics and professionals, mainly in engineering applications involving financial decisions associated with nonfinancial attributes (Dağdeviren 2008; Ahmed and Qiu 2009). Furthermore, AHP is an evaluation method of the hierarchy of attributes with applications in several areas of the social sciences mainly because it allows qualitative and subjective analysis to become operational through numeric features.

In the specific analysis case of the selection of IC foundry service providers, AHP allows the "hierarchization" of subjective opinions in considering IC foundry service providers, making possible a quantitative treatment that leads to a numerical estimate of the relative importance of the evaluation criteria. Through AHP, the importance of several attributes is measured with a process of paired comparison, in which the relevance of the attributes or categories of 
Fig. 1 Evaluation hierarchy for IC foundry

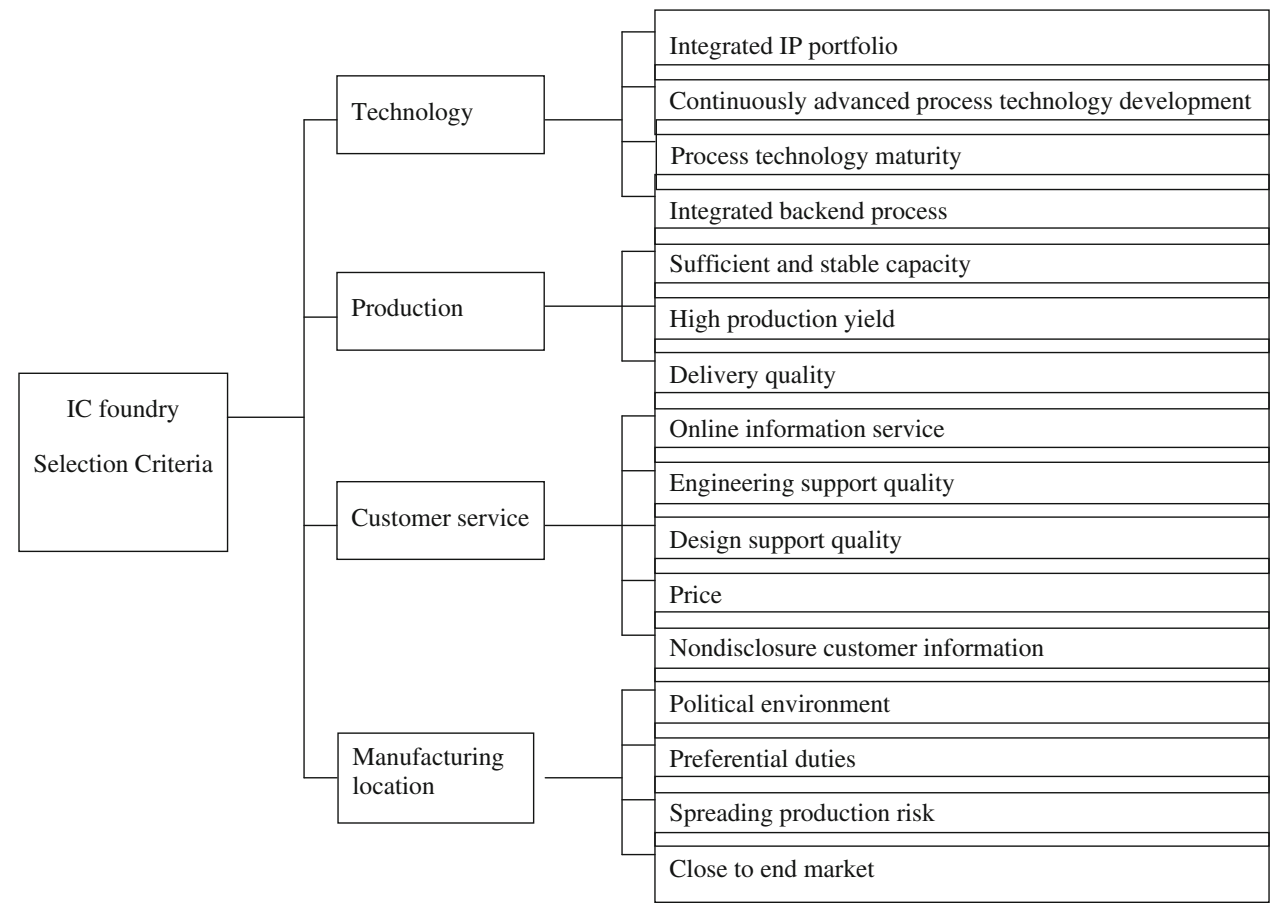

Table 1 Verbal scale for pairs of compared attributes

\begin{tabular}{ll}
\hline Verbal judgment & Numerical rating \\
\hline Extremely preferred & 9 \\
Very strongly preferred & 7 \\
Strongly preferred & 5 \\
Moderately preferred & 3 \\
Equally preferred & 1 \\
\hline
\end{tabular}

Source: Saaty (1980)

evaluation criteria are matched two-on-two in a hierarchic structure. Initially, the management (questionnaire respondents) must compare the several evaluation criteria following the verbal judgment scale presented in Table 1. Intermediate values are possible, and they correspond to the intermediate importance relationships among attributes.

For instance, in comparing the relative importance of evaluation criteria $A_{i}$ and $A_{j}$, if the judgment is 9.00, the management considers that the attribute $A_{i}$ is extremely more important than attribute $A_{j}$ when selecting a good IC foundry service provider. With this procedure, the verbal judgment mechanism composed of the experts' perceptions is transformed into numerical equivalents. Thus, the managers must perform a qualitative comparison of every evaluation criterion against each other, according to the previous table, thus obtaining Table 2.

In the AHP model, if the relative importance of $A_{i}$ as related to $A_{j}$ is $x_{i j}$, the opposite comparison of attribute $A_{j}$ as related to attribute $A_{i}$ is equal to $1 / x_{i j}$. Obviously, the diag-
Table 2 Matrix of paired comparison among n evaluation criteria

\begin{tabular}{|c|c|c|c|c|}
\hline Attribute & $A_{1}$ & $A_{2}$ & $\ldots$ & $A_{n}$ \\
\hline$A_{1}$ & $X_{11}=1$ & $X_{12}$ & & $X_{1 n}$ \\
\hline$A_{2}$ & $X_{21}=1 / X_{12}$ & $X_{22}$ & & $X_{2 n}$ \\
\hline$\cdots$ & & & & \\
\hline$A_{n}$ & $X_{n 1}=1 / X_{1 n}$ & $X_{n 2}=1 / X_{2 n}$ & & $X_{n n}=1$ \\
\hline
\end{tabular}

onal of the matrix of the comparison is equal to 1.00 , since each criterion is compared to itself. Considering the paired comparison's matrix and based on mathematical concepts of eigenvalues and eigenvectors, Saaty (1980) asserted that the relative weights of each attribute may be calculated through the following equation:

$W_{i}^{(j)}=\frac{X_{i j}}{\sum_{i=1}^{n} X_{i j}}$, with $w_{i}=\frac{\sum_{j=1}^{n} w_{i}^{(j)}}{n}$

The relative weights may be submitted to a cardinal comparison. In this way, the evaluation based on multiple criteria is performed by weighting the indicators for attributes of each alternative against the relative weights. AHP allows the identification of a parameter on the consistence level of the relative importance of the attributes, since subjective judgment may present decision biases. This index reflects the coherence level of comparisons among attributes, and it is calculated through the equation below: 
$\mathrm{IC}=\frac{\lambda-n}{(n-1) \beta}, \quad \operatorname{com} \lambda=\frac{\sum_{i=1}^{n} \alpha_{i}}{n}$,

$\alpha_{i}=\frac{\sum_{j=1}^{n} x_{i j} * w_{i}}{w_{i}}$

where $\beta=0.0,0.0,0.58,0.90,1.12,1.24,1.32,1.41,1.45$, and 1.49 for $n=1,2, \ldots, 10$ represents a consistency index of a random paired comparison matrix. Thus, AHP incorporates several attributes into evaluating alternatives and allows for the monitoring of the respondents' coherence related to the judgment of the relative importance of the attributes. The values of $w_{i}$ correspond to the relative weights of each attribute $A_{i}$, and the index IC represents a coherence measurement of the comparative evaluation performed by the respondents. The lower IC, the more consistent are the judgments. Generally, it is considered that the results of the paired comparisons are coherent whenever the consistency indexes are lower than 0.10 (Saaty 1980).

\section{Sampling}

We wished to analyze the evaluation criteria used by IC designers when selecting foundry service providers. This research targeted Taiwan's IC design industry as our major survey sample. Taiwan started IC packaging back in 1966. After a quarter century of learning and growth, the IC foundry and IC design industries in Taiwan have matured. In 1999, there were 98 IC design houses in Taiwan, comprising 22\% of the world's total (Dataquest 1999). According to Taiwan's Industry \& Technology Intelligence Service (ITIS), the production value of Taiwan's IC design industry reached $\$ 9.95$ billion in 2006, while the global production was $\$ 42$ billion, which indicated that Taiwan was the second marketplace of the global IC designs, next to the United States (ITIS 2007).

We then distributed questionnaires to 16 IC design companies in Taiwan, whose yearly operation revenue exceeds $\$ 30$ million on average, including domestic and international computer and related IC product designers, non-durable IC product designers, communication and Internet IC product designers, memory chip IC product designers, and other IC product designers. Eighty seven questionnaires were sent out in total, and the experts/respondents chiefly included top managers (especially at customer service departments and the purchasing departments) of these IC design companies, mostly with over 15 years of work experience. We retrieved 62 questionnaires out of those issued, so the return rate was $71.26 \%$. Then, we selected 49 questionnaires whose consistency ratio $(\mathrm{CR})$ values were smaller than 0.1 among those retrieved as the valid sample for further analysis.
Table 3 Ranks and weights of evaluation concerns for IC foundries

\begin{tabular}{lll}
\hline Rank & Concern & Weight \\
\hline 1 & Technology & 0.42 \\
2 & Customer service and support & 0.27 \\
3 & Production & 0.21 \\
4 & Manufacturing location & 0.10 \\
\hline
\end{tabular}

Table 4 Top 5 evaluation criteria for IC foundries

\begin{tabular}{lll}
\hline Rank & Criteria & Weight \\
\hline 1 & Process technology maturity & 0.197 \\
2 & Price & 0.140 \\
3 & Continuously advanced process & 0.122 \\
4 & technology development & 0.099 \\
5 & High production yield & 0.087 \\
\hline
\end{tabular}

Evaluation results

Our results in this section can be deemed trustworthy. Regarding the reliability, this research used internal consistency reliability as the testing method. The CI and the CR of AHP were also applied to estimate the internal consistency reliability: inequations, C.I. $\leqq 0.1$ and C.R. $\leqq 0.1$, were used to test the reliability of the questionnaire. In addition, the questionnaire met the theoretical requirements with acceptable internal consistency reliability.

The validity is concerned with both nomological validity and content validity. Since this research integrated theories from other researchers while developing the questionnaire on different levels, the contents of the questionnaire should be reasonable in terms of the nomological validity. Furthermore, under the review of several experts and scholars, the constructs and criteria were affirmed to have clear expression and to effectively measure the objectives. Thus, the questionnaire should have a certain degree of content validity.

The following analyses indicate the relative importance of the top-level concerns and the second-level evaluation criteria of IC designers regarding the selection of IC foundry service providers. The top-level concerns of IC designers were technology (0.42), customer service and support (0.27), production (0.21), and manufacturing location (0.10). Of the 16 evaluation criteria, process technology maturity was ranked most important at 0.197 . Next was price at 0.140 . Third was continuously advanced process technology development at 0.122 . The relative ranks and weights given by IC designers are shown in Tables 3 and 4.

Through the AHP survey, we found that IC designers view process technology as the most important factor when they select appropriate IC foundry service providers with which 
to venture. This result has been at some level accordant with prior research claims as noted before (e.g., Shyu et al. 2003). However, adding in other literature's concepts, we hope our model as well as results can hold more truth to nature. There are also some other worthy issues that we should emphasize: (1) customers' needs, (2) all aspects of quality, and (3) longterm vision and strategies. In this hyper-competitive era, apart from technology, foundry enterprises need careful and wise strategic planning with a long-term vision in order to sustain their competitive advantages in the marketplace.

\section{Exploring strategies for foundry process technologies}

According to the previous section, foundry process technologies are the most influential factors when IC designers select IC foundry providers. Therefore, in strategic terms, IC foundry providers should develop superior practices in this regard in order to raise their profitability efficiency.

\section{Research process and framework}

Management theories determine the possible strategies firms should employ to maximize profits; the concept of the product life cycle, on the other hand, describes the characteristics and development direction of the semiconductor industry. This section integrated these two perspectives, being the driving force for process development, and further explored the IC foundry process development pattern and the propositions about process strategies employed in different product technology life cycle stages, which are inferred through the case study on TSMC. Briefly, the analysis is based on the framework constructed by business-level general competitive strategies (including cost leadership, differentiation, focus low cost, and focus differentiation) and the product life cycle. Finally, based on the process strategy model and the conclusion, general strategic suggestions on Taiwan's IC foundry process development are proposed.

TSMC is the leading firm of the Taiwanese and global IC industry. Table 5 provides some further data following the same statement as noted before. Since its foundation, TSMC disintegrated the process of IC industry through its dedicated foundry manufacturing; it then created the horizontal division value chain through its "Virtual Factory" system. TSMC President Morris Chang founded this company in 1987 with support from the Taiwanese government and capital from the National Development Fund of Executive Yuan, Philips and some local enterprises. TSMC became the first company dedicated to providing manufacturing services of ICs for clients (IC foundry). A further case study on global IC foundry king TSMC should furnish highly valuable research outcomes and strategic implications.
Table 5 Top ten foundry companies and their estimated market shares in 2007

\begin{tabular}{llllcl}
\hline $\begin{array}{l}2007 \\
\text { Ranking }\end{array}$ & Company & Country & $\begin{array}{l}\text { Revenue } \\
\text { (US dollars/ } \\
\text { million) }\end{array}$ & $\begin{array}{l}\text { Growth } \\
(\%)\end{array}$ & $\begin{array}{l}\text { Market } \\
\text { share } \\
(\%)\end{array}$ \\
\hline 1 & TSMC & Taiwan & 9,813 & 1 & 47.0 \\
2 & UMC & Taiwan & 3,755 & 2 & 18.0 \\
3 & SMIC & China & 1,550 & 6 & 7.4 \\
4 & Chartered & Singapore & 1,458 & -5 & 7.0 \\
5 & TI & U.S. & 610 & 4 & 2.9 \\
6 & IBM & U.S. & 570 & -5 & 2.7 \\
7 & Dongbu & S. Korea & 510 & 12 & 2.4 \\
8 & Vanguard & Taiwan & 486 & 22 & 2.3 \\
9 & X-Fab & Europe & 410 & 41 & 2.0 \\
10 & Samsung & S. Korea & 385 & 413 & 1.8 \\
\hline
\end{tabular}

Source: IC Insights (2008)

Data collection and case study analysis

Next, a case study on TSMC was conducted. Sources of data included secondary data and interviews with TSMC employees. Reports from journals and magazines in related fields, statistics from research agencies, and company profile and data provided by TSMC were the sources of secondary data; the preciseness of data was validated by experts and scholars. The researchers conducted interviews with related personnel of the case company and further discussed the interview results with experts and scholars. For higher reliability, we targeted TSMC middle to high level managers and engineers as interviewees. These interviewees included directors at the executive level, R\&D managers, senior process engineers, system engineers, sales managers, service managers, and information technology engineers. In addition, every interviewee had more than ten years of professional experience. We targeted these interviewees because we believed that the strategic directions were highly influenced by middle to high level managers. Therefore, their opinions on process strategy issues were based on the empirical rule (Nonaka and Takeuchi 1995).

\section{Business competitive strategy and product life cycle}

In order to proceed with our strategy model building, we injected the following two significant strategy concepts.

Business competitive strategy

Porter (1985, 1998) and Hill and Jones (2003) contended that there are four principle corporate competitive strategies at the business level: cost leadership, differentiation, focus low cost, and focus differentiation (see Fig. 2). Porter 


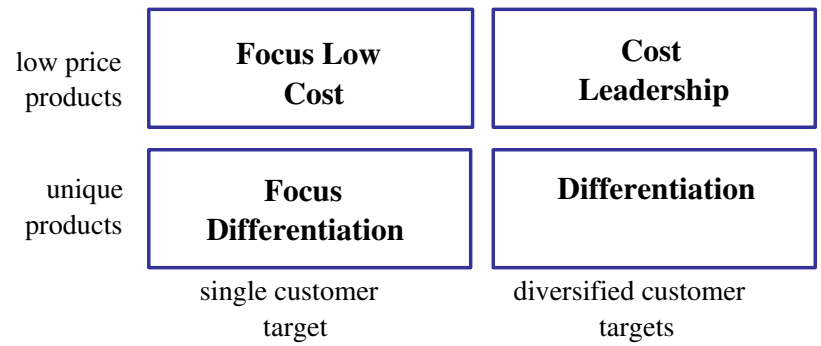

Fig. 2 Business-level competitive strategy

$(1985,1998)$ also argued that a corporation should choose one from each of the following categories, low cost strategies, differentiation strategies, and focus strategies, as the key competitive strategies to develop prominent competitive advantage over the competitors for higher profitability. The low cost advantage and leadership come from the experience curve, economy of scale, and specialization. Differentiation means that the products or service of a firm are distinct from those of competitors, and these properties are valuable to most or some customers. Therefore, creation of customer values is the first priority when employing differentiation strategies. The focus strategies suggest a firm focus on a specific customer group, product line, or regional market; a firm can then achieve a higher than industrial average level of profitability through the low cost or differentiation advantages. Focus strategies concentrate on some specific market segments to establish the market position for a firm. However, these segmented markets are neither the largest nor the most important ones. It takes different skills and resources to support these four general competitive strategies. These strategies also imply different organizational arrangements, control procedures, and invention systems. After considering the strategies of competitors, a firm should pursue the niche markets that competitors have not entered, thus according its advantages.

Management tends to work with a firm's current advantages to form its general strategies, and therefore, Porter (1998) provided three practical suggestions on strategy formation:

1. Positioning: position a firm in a competitive strategy group to maximize the capability of its functions with best defense and maximum competitive advantage against competitions.

2. Influencing the balance status: use strategic actions to influence the balance of competitive positions in order to improve a firms' comparative competitive advantage.

3. Seizing the chance for environmental change: use a proper strategy to utilize the chance for environmental change in order to gain a leading advantage.

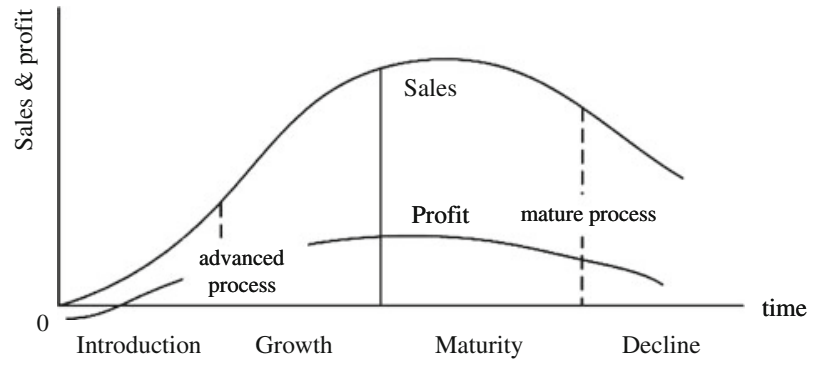

Fig. 3 Technology process and the product life cycle

Product life cycle

Product life cycle is an important concept in industrial evolution analysis, product planning, and strategy implementation (Smallwood 1991; Ansoff 1984). Products come with different characteristics as they are in different stages of the product life cycle, and thus, they require different marketing, finance, manufacturing, purchasing, and personnel strategies to strengthen products' competitiveness in the dynamic competition environment (Rink and Swan 1979; Kotler 1994). The firm would redefine its competitive strategies during a product's life cycle due to the change of economic situation, attack from competitors, and the shift of customers' interests and needs. Therefore, a firm must determine which stages of the product life cycle its products fall within, and it can then adopt effective measures to extend product life and expand profitability.

According to McCarthy (1979), the life cycle of an industry portrays the product life cycle of all the firms' products in that category. If a firm's product life cycle is different from the industrial life cycle, this firm obviously needs to adjust its product modeling or branding strategies or eventually change to another strategy. Kuo (1984) suggested that one should employ the product modeling strategy and the product branding strategy alternately or jointly to strengthen the vigorousness of one's product category. In fact, a product's life cycle is closely related to its market size. Besides product innovation and market planning, control, such as old product/new market, new product/new market, or old product/new usage/new market, can also increase a product's surviving energy in the market (Wells 1968).

General studies about the product life cycle describe a product's selling situation with an S-shape curve and typically divide it into four stages: introduction, growth, maturity, and decline (Rink and Swan 1979). Due to the overlapping of strategies in product life cycle stages and the characteristics of IC foundry process development, this research integrates those product life cycle stages into two stages: advanced-technology process and matured-technology process (see Fig. 3). 
1. Advanced-technology process:

a. Introduction: a new product enters the market with slow sales growth and low margin.

b. Growth: the product is accepted by the market rapidly with fast sales growth and increasing margin.

2. Matured-technology process:

a. Maturity: the product is accepted by most potential customers with a slowing sales growth and steady margin.

b. Decline: sales drop rapidly, and the margin declines.

\section{IC Foundry process strategy model and propositions development}

This section constructed an IC foundry process strategic structure based on the general corporate competitive strategies of cost leadership, differentiation, focus low cost, and focus differentiation together with the concept of the product technology life cycle. Then, we developed propositions regarding the process strategies for different product technology life cycle stages through the case study on TSMC.

The structure of IC foundry process strategy model

The costs of IC foundry for IC design houses can be divided into pilot run costs and production costs: the cost of masks is the major part of pilot run costs and the production cost is closely related to the price of each wafer, the number of dies that can be cut from each wafer, and the yield rate. Advanced processes require more expensive masks and wafers. The major difference between advanced processes and matured processes is that the yield rate of advanced processes can be improved through engineers' efforts and that of matured processes can hardly be improved due to the limits of physical laws.

Differentiation means that a firm has the capability of satisfying customer needs at a level the competitors cannot reach; therefore, this unique ability to compete leads to increased profits as firms can charge customers premiums. For IC foundry firms, understanding customer needs and developing unique competitiveness is the key to create differentiation. Firms employing focus law cost strategies will compete with the cost leader in the market segments where they do not have cost disadvantage. These firms can obtain cost advantage in the production process of customized products or the complicated products whose experience curve cannot be achieved by the cost leader's economy of scale. Mass-production standardized product markets are then left for the cost leader. Firms employing focus differentiation strategies will concentrate on a small range of products instead of trying to serve all market segments; otherwise, they will have to compete directly against firms using differentiation strategies. Therefore, this research proposed the following IC foundry process strategy model: (1) advanced process cost leadership, (2) matured process cost leadership, (3) advanced process differentiation, (4) matured process differentiation, (5) advanced process focus low cost, (6) matured process focus low cost, (7) advanced process focus differentiation, and (8) matured process focus differentiation.

The development of IC foundry process strategy propositions

Below are the propositions deduced by this research through the case study on the key global IC foundry firm, TSMC.

Proposition 1 IC foundry advanced process low cost strategies include reducing the pilot run cost, increasing yield rates, and shrinking chip size.

1. Reducing the pilot run cost: The price of masks keeps rising as the semiconductor process technology reaches the nanometer age; the cost of a $90 \mathrm{~nm}$ process mask set can reach millions of US dollars. Small IC design companies cannot afford the failure of one new type out (NTO), and even those medium-size IC design houses with $\$ 100$ million in capital will be bankrupt if they fail in several NTOs. Only the large IC design companies are capable of developing advanced process ( $90 \mathrm{~nm}$ process) ICs. Therefore, TSMC launches so called CyberShuttle service: clients can reduce their NTO costs through sharing a multiple-NTO wafer. This service can develop potential clients for TSMC, and it makes advanced processes available to smaller IC design firms.

2. Increasing yield rates: At different process development stages, TSMC employs different low cost process strategies, such as the yield improvement of advanced processes and the process simplification of matured processes. The purpose of increasing the yield rate is to increase the number of dies being cut from one wafer, and the purpose of process simplification is to reduce production costs effectively; both are low cost process strategies. However, the implementation of increasing yield rate strategies is focused on the earlier stage of process development, as the yield rate improvement slows in the later stage, and the costs usually increase while trying to further improve yield rates. However, there are theoretical limits on increasing yield rates.

3. Shrinking chip size: Take the example of TSMC's process development from the 0.13 - $\mu \mathrm{m}$ generation to the 90 -nano generation. A 90-nano transistor is only half the size of a $0.13-\mu \mathrm{m}$ transistor. The chips with the same functions produced by the 90-nano process are only half the size of 


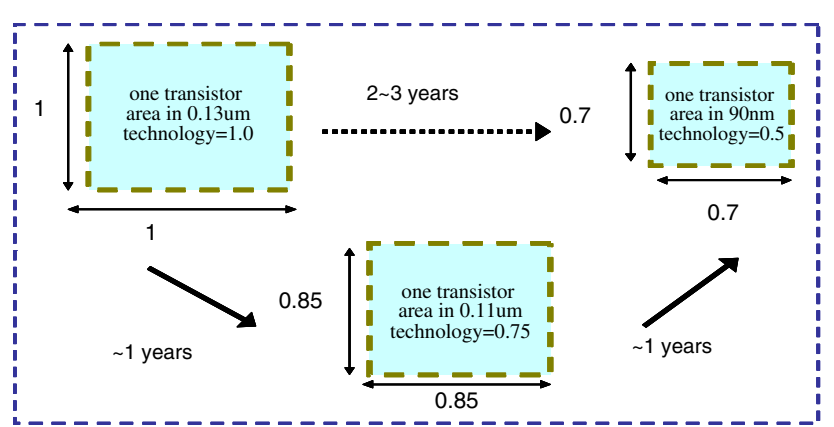

Fig. 4 The concept of chip size shrinking

those produced by the $0.13-\mu \mathrm{m}$ process, and therefore, the cost of each IC chip drops remarkably. Since there are two to three years lag between 90-nano process technology and $0.13-\mu \mathrm{m}$ process technology, a process technology between the $0.13-\mu \mathrm{m}$ and 90 -nano ones would be helpful on the accumulation of IC foundry process experience or the reduction of costs to IC design houses. The $0.11-\mu \mathrm{m}$ process technology was motivated by such ideas; as Fig. 4 indicates, the launch time of the $0.11-\mu \mathrm{m}$ process was around 1 year later than that of $0.13-\mu \mathrm{m}$ process while the degree of $0.13-\mu \mathrm{m}$ yield rates improvement was limited, and 90-nano technology was not ready for mass production. The $0.11-\mu \mathrm{m}$ process emerged in time for the production of smaller chips with low cost and high performance advantages over the $0.13-\mu \mathrm{m}$ process. Therefore, next-generation process technologies, such as $0.22-\mu \mathrm{m}$ (the next-generation of $0.25-\mu \mathrm{m}$ ), $0.15-\mu \mathrm{m}$ (the next-generation of $0.18-\mu \mathrm{m}$ ), and $0.11-\mu \mathrm{m}$ (the nextgeneration of $0.13-\mu \mathrm{m}$ ) have become important parts of TSMC's technology development roadmap.

Proposition 2 IC foundry matured process low cost strategies include reducing pilot run costs and process simplification.

1. Reducing the pilot run cost: The methods and ideas of CyberShuttle services (see Fig. 5) for matured and advance processes are the same. The only difference is that the mask for matured processes is much cheaper. The CyberShuttle makes the mask even cheaper, working very well for the IC design firms with many product lines but small in quantity or those small-to-medium IC design firms with limited capital (like most IC design houses in Taiwan). TSMC provides CyberShuttle service covering from the most matured $0.35-\mu \mathrm{m}$ process to the most advanced 90 -nano process.

2. Process simplification: The process simplification strategy is implemented at the later stage of process development because, by then, designers have accumulated certain amount of knowledge and experience about that
Traditional mask:

duplicated devices in one set of mask, need 6 set of masks for 6 different devices

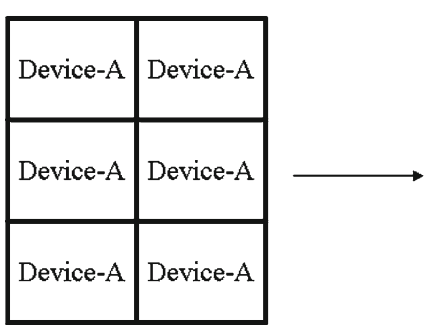

CyberShuttle mask:

multiple devices share same mask set, in the example, 6 different devices only need one set of mask.

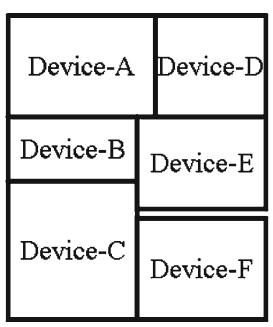

Fig. 5 CyberShuttle service

process to improve it with no effect on the yield rates. The process simplification strategies of TSMC can be classified into two categories: software improvements for reducing process steps and hardware improvements for increasing machine utilization. The process steps reduction includes the major rearrangement of mask number reduction and process steps omission or integration and minor rearrangement of minor adjustments in the process recipe. The machine utilization improvement focuses on expanding the life cycle of machines' consumables and expanding machine functions for better production arrangements and schedules. The IC manufacturing processes require specific machines, and therefore, increasing the number of recipes on each machine can improve productivity effectively.

Proposition 3 IC foundry advanced process differentiation strategies include system-on-chip (SoC) process development, market-oriented process development, next-generation process development, and customer-oriented services.

1. SoC process development: The two types of TSMC's advanced SoC process development include high density memory (HDM) and mixed signal/radio frequency (MS/RF). High density memory is a type of static random access memories (SRAMs). Generally speaking, SRAM occupies the largest area on SoC products. Therefore, the IC foundry firm using a HDM process would be able to provide differentiation service. TSMC's HDM product lines from 1T-P of $0.25-\mu \mathrm{m}$ to $0.15-\mu \mathrm{m}, 1 \mathrm{~T}-\mathrm{Q}$ of $0.13-\mu \mathrm{m}$, to the latest 1T-MiM of 90-nano have fit the term "high density" better and better. Compared with traditional SRAM-structure chips, 1T-P and 1T-Q have been reduced to one-third in size, and 1T-MiM can be further reduced to one-fifth of the original size. Since analog signals are widely used in communications, information technology, and consumer products, they require analog/high frequency signals to complete their specific functions; in contrast, traditional logic circuits and mem- 
ories are digital signals. The MS/RF process allows both types of signals on one IC chip.

2. Market-oriented process development: There are three groups in TSMC's 90-nano family, including generic (G) processes, generic turbo (GT) processes, and low power (LP) processes. Clients can select their process services according to different market applications. For example, LP processes can be used on mobile phone or notebook computer ICs, GT processes can be used on graphic chips or microprocessors, and $\mathrm{G}$ processes can be used on consumer product ICs. For each type of process, TSMC further provides differentiation options, such as voltage (Vt), input/output circuits (IO), and SRAM. The Vt option provided by TSMC optimizes the speed and performance for IC design houses. TSMC offers different IO circuit and operating voltage choices to satisfy all kinds of applications. Differentiation SRAMs are also provided, from the size optimized high density memory to speedy high current memory.

3. Next-generation process development: Next-generation processes are not only the result of low cost strategies but also the result of transistor shrinkage and performance upgrade. TSMC's next-generation process has been the most advanced in the market. For example, the $0.11-\mu \mathrm{m}$ process being launched one to two years after the $0.13-\mu \mathrm{m}$ and before the 90-nano process was the most advanced process technology.

4. Customer-oriented services: TSMC's customer-oriented services of process development have been widely researched by academics. TSMC defines itself as clients' virtual fab (VF), which means that through the business interaction with TSMC, clients can obtain the benefits of in-house fabrication but without the risk of capital investment. TSMChas implemented "TSMC-Online," "TSMCDirect," and "TSMC-YES" to realize VF services.

Proposition 4 Niche process development is the IC foundry matured process differentiation strategy.

\section{HV and LCOS niche process development: TSMC's high-} voltage (HV) process development can be classified into DDD-MOS and LDMOS groups according the structure of transistor: LDMOS focus on $40 \mathrm{~V}$ plus application market while DDD-MOS are applicable in the 5 to $40 \mathrm{~V}$ market. Niche process development, such as HV process technology, has been one of the differentiation strategic options since the mature process production facilities become available after logic IC switched to high-end process. According to the difference of display, projection TV technology can be classified into LCD, DLP, LCOS, and CRT rear projections. The 0.35-, 0.30-, and 0.25- $\mu \mathrm{m}$
LCOS process services of TSMC are also mature process differentiation strategies.

2. SiGe niche process development: $\mathrm{SiGe}$ is created by adding germanium $(\mathrm{Ge})$ to a silicon ( $\mathrm{Si}$ ) semiconductor. $\mathrm{SiGe}$ process development has both the advantage of cost and integration similar to CMOS, and high frequency and high speed properties similar to GaAs. Therefore, the SiGe process has taken over the position of GaAs process in wireless communication applications because of its high CMOS process integration. TSMC currently provides SiGe IC foundry services on 0.35 - and $0.18-\mu \mathrm{m}$ technology nodes. Like HV process technology, the SiGe process belongs to the matured niche process development strategies not only due to capacity utilization but also because of the several-generation technology lag between non-logic and logic processes.

Proposition 5 Increasing customization yield rates is the IC foundry advanced process focus low cost strategy.

1. Increasing customization yield rates: Because of the complexity of IC, TSMC will tune the process to optimize individual clients' IC performance according the results of pilot runs and its mass production experience even though these clients use the same process. This way of increasing customization yield rates can be viewed as TSMC's advanced process focus low cost strategy.

Proposition 6 Customized next-next-generation process development is IC foundry matured process focus low cost strategy.

1. Customized next-next-generation process development: The example of TSMC's next-next-generation process technology is the miniature of $0.15-\mu \mathrm{m}$ process technology (called 0.14- $\mu \mathrm{m}$ ), and it was launched at the end of 2002 when $0.13-\mu \mathrm{m}$ was the most advanced process technology while the $0.14-\mu \mathrm{m}$ was the realization of matured $0.15-\mu \mathrm{m}$ process technology low cost strategy. TSMC's matured processes (such as 0.18 - and $0.15-\mu \mathrm{m}$ ) were insufficient then, and the yield rates of matured processes among competitors are similar. Therefore, TSMC shrank clients' $0.15-\mu \mathrm{m}$ layouts directly for production, and it could yield 10-20\% more ICs on one wafer. Since clients could cut more ICs from one wafer, they then enjoyed the lower averaged price of each IC while TSMC kept their price of each wafer and squeezed some capacity for other orders.

Proposition 7 Customized process development is the IC foundry advanced process focus differentiation strategy. 
1. Customized process development: The R\&D of advanced processes is a very risky investment for most integrated device manufacturers; the standardized process service cannot in effect meet their customers' needs fully, and therefore, there comes the "phase in," simply speaking. In other words, IC foundry firms tailor a brand new process development for a specific customer. IC foundry firms including TSMC usually provide this focus differentiation process development service only to the heavyweight customer with potentially large orders because it takes huge amounts of capital, time, and human resources to develop a new process.

Proposition 8 Niche customized process development is the IC foundry matured process focus differentiation strategy.

1. Niche customized process development (CIS): Niche customized process development can be regarded as one kind of "phase in." In contrast to the advanced logic process of ordinary phase in, the process mentioned here mostly uses old fabs and facilities for production with tailor-made processes for clients. This strategy is then regarded as the matured process focus differentiation strategy. The demand for CMOS image sensors (CIS) increase rapidly with the booming of the digital camera, camera phone, and surveillance system markets. TSMC provides CIS process services ranging from $0.5-\mu \mathrm{m}$ process to $0.18-\mu \mathrm{m}$ process, constituting the widest range of CIS process services among IC foundry firms.

2. Niche customized process development (MEMS): Since the precise level required for micro-electro-mechanicalsystems (MEMS) production is lower than the requirement for CMOS processes, MEMS attracts IC foundry firms with old processes and facilities already amortized to make more profits. The phasing out silicon chip process technology in the micro-electronics field has become the leading technology in the MEMS manufacturing. An American company even uses its own sixinch fab to produce back-end MEMS structures while becoming TSMC's IC foundry client for its $0.6-\mu \mathrm{m}$ logic circuits.

\section{Summary}

Following the above, we inferred an IC foundry process strategic pattern and propositions through the case study on TSMC. Table 6 summarizes the inferences below:

1. Advanced process low cost strategies: At this stage, the most important task for IC foundry firms is to reduce clients' costs on masks. As the price of IC drops expo- nentially following Moore's Law, shrinking chip size to increase the number of dies being cut from a wafer and increasing yield rates together becomes IC foundry firms' advanced process low cost strategy, aiming to maintain their profits and bring the benefits of lower costs to their clients.

2. Matured process low cost strategies: At this stage, besides IC foundry firms' matured process low cost strategy of reducing the pilot run costs, cutting the costs of IC foundry through process simplification become these firms' major objective.

3. Advanced process differentiation strategies: The roadmap of semiconductor process technology development has been defined, that is, every 24 months, the technology advanced to the next generation. The discontinuous progress of technology happens every 24 months-the old generation process becomes mature, and the new generation process is unstable. If an IC foundry firm can provide its customers with a next-generation process to smooth out the discontinuous situation, it is then capable of offering the most suitable process solution at any stage. Since IC technology has become more complex, the traditional single process technology cannot satisfy all the market application needs. For example, desktop computers require strong functions while portable electronic devices require low energy consumption design. The coming age of SoC means that ICs with different functions will be integrated into one IC chip. In order to reach this objective, IC foundry firms have to consider the compatible problems at an early stage of process development. Therefore, market-oriented process development and SoC process development are advanced process differentiation issues.

4. Matured process differentiation strategies: The key difference between advanced process and matured process differentiations is the development of the SoC process. According to the semiconductor technology development roadmap, logic and DRAM processes are always at the forefront of technological development, and they also have the largest market share. Analog circuit processes, non-volatile memory processes, and high-voltage processes are one or two generations behind. Therefore, matured process differentiation strategies should target the development of these niche processes.

5. Advanced process focus low cost strategies: Because of the differences with design styles and the complexities of IC process between IC design houses or even between teams from the same company, the variance of defect densities between different products using the same process is then remarkable. Consequently, IC foundry firms must improve the customized yield rates on individual IC chips in addition to the general improvement of yield rates in order to save the concerned costs. 
Table 6 Foundry process strategies

\begin{tabular}{|c|c|c|}
\hline \multirow{2}{*}{$\begin{array}{l}\text { IC foundry process } \\
\text { development } \\
\text { strategies }\end{array}$} & \multicolumn{2}{|l|}{ Process technology life cycle } \\
\hline & Advanced process & Matured process \\
\hline \multicolumn{3}{|l|}{ Business level strategy } \\
\hline Cost leadership & $\begin{array}{l}\text { - Yield improvement } \\
\text { - Pilot run cost reduction } \\
\text { - Chip size reduction }\end{array}$ & $\begin{array}{l}\text { - Process simplification } \\
\text { - Pilot run cost reduction }\end{array}$ \\
\hline Differentiation & $\begin{array}{l}\text { - SoC process development } \\
\text { - Market oriented process development } \\
\text { - Sub-generation process development } \\
\text { - Customer oriented service }\end{array}$ & $\begin{array}{l}\text { - Niche process development (HV and LCOS) } \\
\text { - Niche process development (SiGe) }\end{array}$ \\
\hline Focus low cost & - Customized yield improvement & - Customized sub-sub-generation process development \\
\hline Focus differentiation & - Customized process development & - Niche customized process development (CIS and MEMS) \\
\hline
\end{tabular}

6. Matured process focus low cost strategies: High yield is the consequence of mature process so that "matured process focus low cost strategies" should not focus on the yield improvement which is the main content of "advanced process focus low cost strategies". Instead, next-next-generation process can be developed to lower costs with help from advanced process experience during shrinking the matured process IC layout size.

7. Advanced process focus differentiation strategies: Every IC foundry firm and IDM has its own design regulations as the rules for IC design to meet the characteristics of their processes. Basically, IC design houses will follow the design rules of their IC foundry firms, but this does not apply to IDMs. IDMs will usually release some orders to IC foundry firms due to capacity adjustments; IC foundry firms have to tune their process recipes to accommodate the differences from both parties because IDMs must design their ICs to meet their own process regulations. These kinds of tuning projects are sometimes as complicated as developing a new process. Therefore, the order volumes are normally large enough for IC foundry firms to earn enough profits through advanced process focus differentiation strategies.

8. Matured process focus differentiation strategies: The strategy of matured process focus differentiation is to develop a niche customized process. Niche customized process development has become the key for matured process focus differentiation strategies to solve the problem of decreasing capacity utilization. Some semiconductor processes, such as MEMS and photoelectric application processes, are high individualized. Thus, IC foundry firms should not develop the process before customers request it; IC foundry firms have to work closely with their customers to succeed.

\section{Concluding remarks}

IC foundries are moving full-speed ahead. This is one of the most important times in foundries' history with the electronics industry. Foundries have emerged from a challenging period in the previous decade and have become much stronger today because they are globally focused, restructured, and more committed than ever to true innovation. There are some worthy issues that deserve to be emphasized: (1) customers: treating customers as partners and establishing a win-win situation is the key to current success and thus crucial to continued growth; (2) quality: to build quality into all aspects of foundry business, foundry service providers should find every way to continuously evaluate and improve the quality of every service work for meeting customer satisfaction; and (3) long-term vision and strategies: enduring environmental pressure and reducing any possible business or operation risks are essential in the long run. In this hyper-competitive era, foundry enterprises need careful and wise strategic planning with a long-term vision in order to sustain their competitive advantages.

The goals of this research were two-tiered: The first was to analyze the evaluation criteria used by IC designers when selecting foundry service providers. With an MCDM model considering the aspects of technology, production, customer service and support, and manufacturing location, we interviewed managers and experts of Taiwan's IC design firms, using the AHP survey with 16 attributes, to determine the areas of top concern with respect to foundry evaluation criteria. The second was to use an in-depth TSMC case study to explore the strategic compositions of IC foundries' process development, since process technology has been found, through our survey at the prior stage, to be the most significant evaluation criterion in view of competitiveness in the customer market. Among these, the management logic of 
IC foundry can be characterized by four competitive strategies, namely the cost leadership strategy, the differentiation strategy, the focused customer differentiation strategy, and the focused customer low cost strategy. The concept of the product life cycle was also employed to help to construct our strategic model of IC foundry process development. In total, we concluded eight categories of IC foundry process strategies.

The final thoughts derived from our research are that, for the foundry industry, technology no longer counts for everything, although it is a priority; coordinated strategies, in contrast, should assure more business merits for all concerned. In other words, a consummate management system and persistent business management concept are important factors to ensure success in the foundry industry. This study has drawn the matrix of foundry process strategies. We hope that the results can facilitate the movement toward amelioration of foundry manufacturing operation.

Being the largest and most successful dedicated IC foundry operator, it is important for Taiwan to put more resources into manufacturing facilities and capacity than nearly anyone else and continue to be the trusted source to a global collection of innovative and savvy businesses, large and small, who appreciate the steadily increasing manufacturing capacity and consistent volume production levels. In addition, the transformation of the business model from IDM to foundry has produced an impressive outcome of historical performance. Based on the proposed model, this research suggests Taiwan-based TSMC and UMC (the top two IC foundry operators in the world) apply the focused differentiation development strategy on the matured manufacturing processes of its 6- and 8-inch fabs and look at investing in 12inch IC manufacturing technology in order to maintain their lead position and continue to accommodate most IC designers' needs. In addition, for the new tiger SMIC (in China), the differentiation/cost leadership strategy of advanced manufacturing processes is suggested to improve its management and market performance.

\section{References}

Ahmad, N., \& Qiu, R. G. (2009). Integrated model of operations effectiveness of small to medium-sized manufacturing enterprises. Journal of Intelligent Manufacturing, 20(1), 79-89.

Ansoff, H. I. (1984). Implanting strategic management. New Jersey: Prentice-Hall.

Chen, G. R., Lu, T. E., Chen, M. L., \& Hsieh, T. R. (2004). An environmental and strategic analysis for current IC foundry in Taiwan. Review of Taiwan Economics, 9(4), 69-82.
Chu, M. T., Shyu, J. Z., \& Khosla, R. (2008). Measuring the relative performance for leading fabless firms by using data envelopment analysis. Journal of Intelligent Manufacturing, 19(3), 257-272.

Corner, J., Buchanan, J., \& Henig, M. (2001). Dynamic decision problem structuring. Journal of Multi-Criteria Decision Analysis, 10(3), 129-142.

Dağdeviren, M. (2008). Decision making in equipment selection: An integrated approach with AHP and PROMETHEE. Journal of Intelligent Manufacturing, 19(4), 397-406.

Dataquest website. (1999). http://dqindia.ciol.com

Hill, C. W. L., \& Jones, G. R. (2003). Strategic management theory. Boston: Houghton Mifflin Company.

IC Insights website. (2008). http://www.icinsights.com

Industry \& Technology Intelligence Service website. (2007). http:// www.itis.org.tw

Kasanen, E., Wallenius, H., Wallenius, J., \& Zionts, S. (2000). A study of high-level managerial decision processes, with implications for MCDM research. European Journal of Operational Research, 120, 496-510.

Kotler, P. (1994). Marketing management. New Jersey: Prentice-Hall.

Kuo, K. M. (1984). Marketing management. Taipei: San Min Book Co., Ltd.

Lo, M. C., Chang, C. Y., Tzeng, G. H., \& Tseng, F. M. (2005). Development strategies of pure wafer foundries using AHP. ISAHP Conference, Hawaii.

McCarthy, E. J. (1979). Basic marketing. Homewood, IL: Irwin.

Nonaka, I., \& Takeuchi, H. (1995). The knowledge-creating company: How Japanese companies create the dynamics of innovation. New York: Oxford University Press.

Perry, W., \& Moffat, J. (1977). Developing models of decision making. Journal of Operational Research Society, 48, 457-470.

Porter, M. E. (1985). Competitive advantage. New York: Free Press.

Porter, M. E. (1998). Competitive strategy. New York: Free Press.

Rink, D. R., \& Swan, J. F. (1979). Product life cycle research: A literature review. Journal of Business Research, 7(3), 219-242.

Saaty, T. L. (1980). The analytic hierarchy process. New York: McGraw-Hill.

Shyu, J. Z., Yu, H. C., Lee, Z. Y., \& Kuo, L. F. (2003). Using fuzzy MCDM method to study the evaluation criteria and location preferences on foundry service providers by IC designers. Journal of Management, 20(2), 219-249.

Smallwood, J. E. (1991). The product life cycle: A key to strategic marketing planning. In B. M. Enis, K. K. Cox, \& M. P. Mokwa (Eds.), Marketing classics: A selection of influential articles. New Jersey: Prentice Hall.

Triantaphyllou, E. (2000). Multi-criteria decision-making methods: A comparative study. Norwell, MA: Kluwer.

Tzeng, G. H. (1977). A study on the PATTERN method for the decision process in the public system. Japan Journal of Behaviormetrics, $4(2), 29-44$.

Tzeng, G. H., Shian, T. A., \& Lin, C. Y. (1992). Application of multi-criteria decision making to the evaluation of new energy-system development in Taiwan. Energy, 17(10), 983-992.

Tzeng, G. H., \& Tsaur, S. H. (1993). Application of multi-criteria decision making to old vehicle elimination in Taiwan. Energy and Environment, 40(3), 265-283.

Wells, L. T. J. (1968). A product life cycle for international trade? Journal of Marketing, 32(3), 1-6. 